\title{
A Review of Environmental Interpretation Research in the West in the Past Decade
}

\author{
Tian'e Cheng \\ College of Urban \& Environmental Sciences \\ Northwest University \\ Xi'an, China 710127
}

\author{
Mingming Cao \\ College of Urban \& Environmental Sciences \\ Northwest University \\ Xi'an, China 710127
}

\author{
Jun Wang* \\ College of Geography Science \\ Shanxi Normal University, \\ Linfen, China 041000 \\ *Corresponding Author
}

\begin{abstract}
Playing a vital role in sustainable tourism, environmental interpretation is an effective tool for visitor management and tourism resource protection. The present study selected some famous academic journals in the field of tourism and reviewed the studies of environmental interpretation research. Findings indicated that in the past decade, environmental interpretation research mainly focused on characteristics of effective personal interpretation and interpretive programs as well as interpretation outcomes. Most studies adopted quantitative methods and data were collected via questionnaire surveys and interviews. Countries like America, Australia, Canada, New Zealand etc. attached importance to interpretation research and the settings involved in the research were mainly national parks, outdoor recreation and entertainment settings, wild life reserves and nature-based settings etc. It was found that interpretation studies gradually shift to visitors' affective outcomes. The author of this study holds that future interpretation research should base empirical studies on appropriate theories and scientific measurement tools. In addition, interpretation at cultural heritage settings should be taken into consideration.
\end{abstract}

Keywords-environmental interpretation; interpretation outcome; interpretive program; knowledge gain; behavioral intention

\section{INTRODUCTION}

The top executives of National Park Service have long viewed that environmental interpretation serves as the most economical method of visitor management ${ }^{[1]}$. Meanwhile, interpretation also has a function of protecting tourism resources. Interpretation has multiple goals such as enhancing visitors' experience quality, protecting visitors' safety, helping visitors gain knowledge, cultivating positive attitudes toward natural and cultural heritage resources as well as pro-environmental behaviors among visitors (Ham,

Funded by the Research Projects: A Study of Optimization of Interpretive System in Tourist Destinations in Shaanxi (2013JK0301); Teaching Team of Translation Courses at Northwest University (JX13058).
Weiler, 2006) ${ }^{[2]}$.The research into environmental interpretation began in the 1960s and the studies involved connotations of interpretation, interpretation planning, outcomes of interpretation and interpretation evaluation tools et al. Quantitative methods are usually adopted and data are collected through questionnaire surveys and interviews. Such empirical studies are often based on theories borrowed from various fields such as sociology, psychology, geology et al and the study sites mainly involve national parks, recreation areas, wildlife reserves, botanical gardens, and nature-based sites et al. in the U.S.A, Australia, New Zealand, Canada, the UK and so on. The author of this paper studied the wellknown academic journals in tourism field such as Tourism Management, Journal of Travel Research, Journal of Interpretation Research, Annals of Tourism Research, Journal of Ecotourism, Journal of Leisure Research, Journal of Environmental Psychology, Journal of Travel \& Tourism Marketing, Journal of Sustainable Tourism, International Journal of Culture, Tourism and Hospitality Research, and reviewed nearly most of the articles on environmental interpretation carried in the above journals from 2006 to 2015. Exploring the research of interpretation from its definition, research contents, theoretical basis and research method, the present study reviewed the latest development in the studies of environmental interpretation in recent ten years, aiming to provide theoretical and empirical basis for further research and to promote the application of the research findings to practice.

\section{THE DEVELOPMENT OF ENVIRONMENTAL INTERPRETATION DEFINITION}

In 1957, Freeman Tilden published the book Interpreting Our Heritage, which established not only the philosophical basis for heritage interpretation but the fundamental principles for interpretation as an $\operatorname{art}^{[3]}$. In his book, Tilden defined interpretation as "An educational activity which aims to reveal meanings and relationships through the use of original objects, by firsthand experience, and by illustrative 
media, rather than simply to communicate factual information" [4]. In the following less than 20 years, interpretation developed into a complicated communication tool, used for influencing visitors' knowledge, awareness, satisfaction, building image for travel agencies and achieving their management goals as well ${ }^{[5]}$.

In the 1960s and 1970s, interpretation focused on the field of ecology and environment. During this period of time, environmental interpretation became a common term in the field of interpretation (Kyle, 2005) and the definitions of interpretation varied among scholars. Brown (1971) viewed that "environmental interpretation is used for imparting environmental knowledge, inspiring discussions about environmental issues and ultimately leading to environmental reform". Mahaffey (1972) held that "environmental interpretation is a particular profession and it is an activity of educating the public in recreational areas and parks." Reyburn (1974) defined environmental interpretation as "environmental interpretation is an educational activity through which people can understand their own function in the ecological system ". Risk(1994) held the view that "environmental interpretation helps to transform professional and more complicated environmental language into nonprofessional language, which aims to enable visitors to develop environmental sensitivity, environmental awareness, resource appreciation and environmental commitment" ${ }^{\text {[6] }}$. In addition to various definitions given by scholars, some wellknown interpretation organizations also defined interpretation. According to Interpret Europe (2014), heritage interpretation is an informal educational activity aiming to provide target visitors with new insight and comprehension. National Association for Interpretation (NAI, 2014) held that interpretation is a task-based communication process which builds an affective and cognitive connection between audience's interests and the meaning inherent in resources. Interpretation Australia (2014) regarded heritage interpretation as a communication between thoughts and feelings to help people know more about themselves and the environment where they live. The British Association for Heritage Interpretation (2014) viewed that interpretation enriches people's life through motivating their emotion, enhancing their experience, deepening their understanding of places, folks, and events as well as objects [7]. Based on what is mentioned above, it can be concluded that the words frequently mentioned in the definitions of interpretation are education, communication, information, interpretation, meaning, understanding et al. Generally speaking, interpretation can be viewed to provide information for non-captive audience in museums, zoos, cultural heritage sites, parks et al through means of communication, motivation and entertainment et al. Researchers may name interpretation as environmental interpretation, heritage interpretation, museum interpretation, tourism interpretation et al. based on their selected study sites. Although different terms may be used, the essence of interpretation remains the same.

\section{STUDY CONTENTS INVOLVED IN ENVIRONMENTAL INTERPRETATION RESEARCH}

Interpretation includes personal interpretation and nonpersonal. Personal interpretation refers to on-site interactive interpretation for the visitor, such as interpretation given by interpreters, tour guide, organized activities et al. (Hughes, $2004)^{[8]}$. Non-personal interpretation refers to interpretive services delivered through interpretive media like signage, brochures, exhibits, self-guided tours, websites et al.. It is generally believed that personal interpretation has stronger impact on audience than non-personal interpretation. Wearing and Neil (1999) argued that personal interpretation enables representatives of tourism management to conduct two-way dynamic communication with visitors while nonpersonal interpretation is a one-way static communication with lower interaction and visitors themselves need to understand the meaning of tourism resources through interpretive media. Therefore, the impact of such interpretation on audience is weak (Hughes, 2004: P49). According to statistics, about $22 \%$ of visitors use personal interpretation and more than $62 \%$ of visitors use nonpersonal interpretation (Forist, 2003) ${ }^{[9]}$. Despite the above mentioned fact, scholars in the West have conducted thorough studies on both personal interpretation and nonpersonal interpretation, focusing mainly on tour guide interpretation, non-interpretive service program and visitors to explore characteristics of excellent interpretive services.

\section{A. Studies Concerning Characteristics of Effective \\ Personal Interpretation and Non-personal Interpretation}

1) Studies focusing on tour guide interpretation and other interpretive media: Rosemary Black and Penny Davidson (2013) surveyed 30 Australian tour guides about interpretation skills and put forward the following 9 principles for effective interpretation: interest, relative, logic, thematic, team management, protecting visitors, two-way communication with visitors, serving visitors and affective influence ${ }^{[10]}$. Man-U Io (2013) created an interpretation model which held that interpreter's knowledge, service attitude, communicative competence and emotion quotient affect visitors' travel experience positively. Besides, the model has been verified in empirical studies which emphasized that training class for tour guides should attach importance to affective management of visitors since this is the key factor to enhance visitors' emotional involvement and experience ${ }^{[11]}$. Marc Stern and Robert Powell (2014) studied 376 interpretive programs in national parks in the U.S. and found effective personal interpretation involved confidence, true feeling involvement and personal charm demonstration, timely response to visitors' questions and requests et al. and should avoid taking knowledge gain as the goal of interpretation. Excellent interpretive programs feature appropriate contents, texts with clear logic, definite information and reasonable logic et $\mathrm{al}^{[12]}$. Jonathan Ivey and Robert Bixler (2013) conducted a study of interpretation content, interpretation skills as well as the importance and validity of interpretation certification. The findings of the 
study indicated that among 32 interpretive skills, the top five are improvisational interpretive skill, having a knowledge of the learning ways of children of different age, understanding the audience, interpreting with measured tones and having the ability to design the syllabus of interpretation $^{[13]}$. In addition to the research into characteristics of effective interpretation conducted by providers of interpretative services, some scholars also conducted research of characteristics of good interpretation.

2) Studies focusing on visitors: Roy Ballantyne (2008) et al surveyed 150 visitors touring a botanical garden in Queensland in Australia and the results showed that inspiring signage or leaflet provided at the entrance might interest visitors' concern about environmental issues[14]. Naoko Yamad and Doug Knapp (2007) surveyed 492 visitors in a national park in Japan to examine their preferences to interpretive services. The findings indicated that $80 \%$ of visitors preferred personal interpretation and enjoyed interactions with interpreters, showing that personal interpretation impacted on visitors' touring experience positively [15]. Yaniv Poria (2009) used visitors visiting the Wailing Wall in Jerusalem as study subjects to explore affective outcomes of interpretation. The results demonstrated that the design of interpretive programs should be based on visitors' preferences and travel motivation since potential visitors hoped that the information provided through interpretation would satisfy their needs because they regarded interpretation not only as an educational activity, but also a factor of emotional involvement [16]. Jessica Goodrich and Robert Bixle (2010) interviewed 57 visitors in a national park in southern U.S. about the restrictive factors that affected visitors' use of interpretive programs. The results showed that the following factors affected the use of interpretive programs, namely, being unable to locate interpretive programs, age brackets, and visitors' stronger desire to participate in other activities instead of interpretive programs et al. According to this study, elaborately designed interpretive programs should be provided and various interpretive techniques should be employed to attain the management goal of national parks [17].

\section{B. Studies Concerning Outcomes of Interpretation}

1) Research into knowledge gain through interpretation: In recent years scholars in the field of interpretation attach importance to outcomes of interpretation and some studies found that interpretation impacted visitors' knowledge gain, satisfaction, environmental protection attitude and environmental behaviors et al. As far as knowledge gain is concerned, some studies investigated variables affecting visitors' knowledge gain, while other studies explored visitors' satisfaction, environmental protection attitude and the change in environmental behaviors based on visitors' knowledge gain. Mandy Harrison and Sarah (2009) in their study found that interpretive services provided by tour guides who received professional training helped visitor gain more environmental knowledge and intrigue their interests in the place visited, showing that knowledge of tour guides and their interpretive skills obviously impact visitors' knowledge gain 18]. Some studies concluded that visitors' knowledge gain helped enhance their travel satisfaction. Mark Morgan and Geumchan Hwang (2014) surveyed 148 Korean visitors at Jefferson National Expansion Memorial and divided them into control group, experimental group 1 and experimental group 2. Visitors in control group didn't use any interpretative service, while visitors in experimental group 1 watched DVD about an introduction to the Gateway Arch and visitors in group 2 were accompanied by a tour guide who provided interpretation for them. The findings of the study showed that visitors from control group developed a weak cognition of the interpretation theme, but the cognition of visitors from experimental groups was improved greatly and that of visitors who were provided with personal interpretation by the tour guide increased most. This study concluded that interpretive programs used by tourists, especially those provided by tour guides were an effective way to enhance visitors' travel experience quality and also an ultimate way to enhance visitors' satisfaction [19]. Some researchers focused their studies on impacts of tourists' knowledge gain on their environmental attitude and behavior change. Jennifer Hill et al (2007) surveyed tourists visiting a tropical rain forest in Queensland, Australia and found that tourists using brochures gain more knowledge about the rain forest than those who didn't. It also found that interpretation helped tourists develop strong environmental sensitivity, but it did not improve their concern for the environment and change their environmental behaviors [20]. Heather Zeppel (2008) studied impacts of interpretation of marine wildlife tours on visitors' knowledge increase and the change in their attitude toward environmental problems. The results showed that the knowledge visitors acquired through contact with marine wild animals helped their on-site pro-environmental attitude change and behavior change [21]. The above empirical studies indicated that environmental interpretation helps visitors increase their environmental knowledge and the knowledge gain helps enhance visitors' tour satisfaction, environmental attitude and behavior change.

2) Studies focusing on visitors' satisfaction: Some researchers mainly investigated impacts of interpretive services on visitors' satisfaction. Sam Ham and Betty Weiler (2007) surveyed 727 national and international tourists in the Panama Canal Watershed (PCW) and the results revealed that the global satisfaction of PCW tourists was due primarily to their satisfaction with the interpretive dimensions of their visit, as opposed to other services and setting attributes. Satisfaction with interpretive services positively impacted on tourist' global satisfaction and tour guide interpretation had a stronger impact on tourists' satisfaction [22]. Robert Powell and Marc Stern (2013) 
explored the relationships among sample size of audience, age bracket, characteristics of interpretive programs, resource quality et al and tourists' satisfaction, tour experience, resource appreciation and behavioral intentions. The results revealed that with larger sample size, tourists' tended to show a more obvious intention the change their environmental behaviors. More children among the audience enabled more visitors to change their environmental behaviors. In addition, outdoor interpretive programs impacted on tourists' visiting experience as well as tourism resource appreciation to a greater degree. What's more, interpreter's confidence, true feeling revelation and personal charm, organizing ability, contact ability, positive response, conveying clear information et al. exerted obvious influence on tourists[23]. Sam Huang et al (2014) surveyed 282 Chinese tourists in an Australian heritage site and the results showed that the cognitive outcomes of interpretation exerted great influence on tourists' satisfaction and their revisit intention. Additionally, satisfaction of tour experience accompanied by tour guide directly impacted on behaviors and coordinated the influence of cognitive outcome of interpretation on behavioral intention [24]. Robert Powell (2014) used the on-site interpretive programs and interpreters in the US national parks as study subjects to construct a model of impacts of interpretive program characteristics and interpreters on tourists' satisfaction, experience, resource appreciation and behavioral intention. The results indicated that interpreters' true feeling investment, logical interpreting and confidence impacted on visitors' satisfaction positively. What's more, the interpretation goals set by interpreters positively influenced tourist' behavioral intentions [25].

3) Studies concerning behavioral intentions: There are relative fewer studies exploring behavioral outcomes of interpretation and the few existing studies have inconsistent findings. Some scholars argued that the ultimate goal of interpretation was to change tourists' environmental behavior and therefore research into behavioral outcomes of interpretation was of great significance. Aise Kim et al (2011) surveyed tourists visiting Lulworth coastal in England and the findings indicated that as far as environmental behavior and local environmental protection were concerned, the outcomes of interpretation were different. Although interpretation fostered visitors' awareness and support of management policy, such impacts were only restricted to visitors' on-site behaviors [26]. Betty Weiler (2009) investigates relationships between cognition, affection as well as behavior of tourists visiting zoos and the number of interpretive media they used. The results found that 288 visitors used 1 to 4 different interpretive media and with an increase in the number of interpretation media used, the impact of interpretation on visitors also increased [27]. Studies of interpretation outcomes demonstrated that interpretation impacts on visitors' knowledge gain definitely, but increasing visitors' knowledge is not the ultimate goal of interpretation. Therefore, some scholars continue to explore satisfaction of visitors' travel experience, environmental attitude change and environmental behavior change on the basis of their knowledge gain. Because the relevant studies are conducted in different study sites and different scales as well as different ways used to collect data, the results of the studies are also different.

\section{THEORETICAL BASIS FOR INTERPRETATION PRACTICE AND INTERPRETATION OUTCOMES}

\section{A. Theoretical Models for Interpretive Program Planning}

The fact that environmental interpretation serves as a tool for sustainable development of tourism has been widely accepted. A few scholars explored models and theories guiding interpretation in the settings of tourism. Ham (1992) studied interpretive programs in nature-based sites and put forward the model of EROT for environmental interpretation based on cognitive psychology. According to EROT model, successful interpretation should include four elements, namely, pleasantness, relativity, logic and theme. Pleasantness indicated that interpretation must make tourist feel pleased and relativity meant that the content of interpretation should be related to audience's life experience. Logic meant that interpretation should be clearly delivered and theme meant that the implication and information contained in the stories involved in interpretation were able to promote visitors' knowledge gain and affective connection (Ham, 1983)[28]. Robert Powell and Ham (2008) employed the model of EROT to an empirical study to investigate whether the elaborately designed interpretive programs in Galapagos National Park in Ecuador impacted on outcomes of environmental education of visitors and their attitude toward environmental support. The results showed that welldesigned interpretative programs helped visitors increase knowledge of the protected area and developed supportive attitude toward resource management, changed their proenvironmental behavioral intentions and attitude toward resource protection. The concept model of interpretive planning proposed by Jon Kohl and Ted Eubanks (2009) combined cultural construction of place meaning with resource protection, viewing that the major function of interpretation was to link visitors with place in order to protect local resources. The model provided a theoretical basis for resource managers, interpretive program planners and interpreters as for how to combine place interpretation with resource protection [29]. Forestell (1990) put forward a three-step interpretation model of "dynamic imbalance of creation, management and solution to cognitive dissonance" which held that there was a linear relationship among knowledge gain, attitude and behavioral change. However, the empirical study conducted by Surya Poudel and Gyan Nyaupane (2013) found that attitude change did not necessarily lead to behavioral change. The inconsistency indicates that the model created by Forestell (1990) needs to be further tested in more empirical studies. In addition to the above models, Elaboration Likelihood Model (ELM) is also used to guide planning of environmental interpretive programs. 
ELM (Petty \& Cacioppo's, 1986) is the most influential theoretical model of custom information processing which holds that information processing includes central route and peripheral route. In the central route, when an individual has a high motivation and ability, he or she would pay more attention to the relevant information about products and his or her careful consideration, analysis and reasoning would lead to attitude change ultimately. In such a route, the motivation is strong and people evaluate relative information based on a large amount of cognitive recourses and eventually make a decision. Attitude change through central route lasts longer and is a more reliable way to predict behavior. In peripheral route, the form and the change of attitude are not a result of positive consideration as well as the characteristics, advantages and disadvantages of products. In fact, the link of products with their positive or negative aspects in ads contributes to the formation and change of attitudes. Using ELM as a theoretical basis, Aise KyoungJin Kim (2011) investigated the attitude and behavioral change of different visitor groups as well as the reasons for such change in order to analyze outcomes of specific interpretation on visitors. The results revealed that interpretive programs should be provided according to audience's interests, cognitive ability and behavior types.

\section{B. Theoretical Basis for Outcomes of Environmental Interpretation}

In studies of behavioral outcomes of interpretation, most of the researchers analyzed visitors' behavioral intentions instead of actual behaviors. It is rather difficult to measure the actual behaviors because measuring actual behaviors takes a lot of time and energy. As a result, most of the empirical studies concerning visitors' behaviors examine change in visitors' behavioral intentions. Theory of Reasoned Action (TRA) and Theory of Planned Behavior (TPB) provide a theoretical support for such studies. TRA (Fishbei \& Ajzen, 1975) holds that an individual's behavior may be reasonably inferred to some degree from behavioral intentions. Meanwhile, an individual's behavioral intention is decided by the attitude toward behavior and the subject norms. TPB (Ajzen, 1991) expands TRA by adding a concept of "perceived behavior control". Perceived behavior control refers to the perception degree to which an individual controls his or her behavior, which is decided by control belief and perceived promotion factor. Both TRA and TPB view that behavior and behavioral intentions depend on individual's belief in the attitude toward to behavior, the consequence of the behavior, social norms and social stress. At a setting of tourism, visitors' behavior, their global environmental knowledge and their attitude are consistent. According to studies concerning TPB, to impact a certain behavior, the first thing to do is affect the attitude related to the specific behavior [30].

Interaction theory is another theory supporting empirical studies of interpretation outcomes. Some researchers argued that interpretive services and the outcomes resulting from such services are a kind of interaction between audience characteristics, visited sites, interpreter and interpretive programs. According to interaction theory, the outcomes on visitors derive from the interaction between characteristics of interpretive services, interpreters, other audience and the settings. Robert Powell and Marc Stern (2013) examined interpretation outcomes of audience characteristics, characteristics of interpretive programs, settings of interpretive programs as well as resource quality. The results showed that the above four factors exert strong influence on visitors.

\section{STUdy METHODS AND MEASUREMENT TOOLS FOR INTERPRETATION RESEARCH}

This paper reviewed studies of environmental interpretation in the past ten years from 2006 to 2015 and found that about $76.92 \%$ studies adopted quantitative methods, $16.92 \%$ of them used qualitative methods and about $6.15 \%$ combined both methods, indicating that quantitative methods dominate the research methods of interpretation in recent ten years. Data for the studies that adopted quantitative methods were collected mainly through questionnaire distribution and interview. Four studies (accounting for $8 \%$ ) collected data through interview with open questions and the sample size for these studies were 166, 21, 50 and 56 respectively, indicating a small sample size for interviews. The rest $92 \%$ studies using quantitative methods collected data by distributing questionnaires, among which only one study conducted the survey online and the rest conducted on-site surveys among visitors. Sample size of 1 to 100 accounted for $23.91 \%, 101$ to 200 took up $17.39 \%, 201$ to 300 occupied 13.04\%, 301 to 400 accounted for $17.39,401$ to 500 took up $8.69 \%$ and the sample size larger than 501 accounted for $15.21 \%$. It can be concluded that sample size smaller than 400 was about $58.69 \%$, indicating that sample size for most of the quantitative studies was under 400, a relatively small sample size. The data were mainly analyzed by using SPSS and structural equation model (SEM) was adopted to test the hypothetical model of variables involved in research. Study sites in the US are about $44.61 \%$, those in Australia took up 20\%, those in Europe accounted for $7.69 \%$ and study sites in other countries such as India, Nepal, Japan, Israel, China and Panama et al were less than 5\%.

One commonly used tool for assessing effectiveness of interpretation was developed by Sam Ham and Betty Weiler (2006). Following a rigorous selection process, they selected 11 indicators to form the core of the Interpretation Evaluation Tool Kit to assess thinking, feeling and behavioral outcomes of interpretation. Three indicators were used to evaluate cognitive outcomes of interpretation, 2 indicators were used to assess affective outcomes and 6 were used for measuring behavioral outcomes. Sam Ham and Betty Weiler tested these indicators repeatedly in three kinds of situations of food \& beverage interpretation, heritage interpretation, and nature interpretation and finally put forward the indicators that suited these three different settings. This evaluation tool was only used for evaluating outcomes of personal interpretation and was not used to assess interpretation outcomes of non-personal interpretation and signage. 
In addition to the evaluation tool designed by Sam and Weiler, another commonly used evaluation tool for measuring behavioral outcomes was developed by SmithSebasto and D'Costa (1995) which consisted of two dimensions, namely general behaviors and specific behaviors. As far as the evaluation of behavioral outcomes of interpretation is concerned, researchers have to adapt the evaluation tool to their empirical studies in order to ensure the scientific results of the research.

\section{CONCLUSION}

Researchers in the West have achieved a lot in interpretation practice and research of interpretation outcomes. Studies of interpretation practice mainly focus on effective interpretive programs and the qualities that interpreter should have, while studies of interpretation outcomes mainly concentrate on visitors' knowledge gain, their environmental attitude change and environmental behavioral change after experiencing interpretive services. A few studies explored actual behavioral change after visitors experienced interpretive services and very few studies examined other outcomes of interpretation such as social norms (Cialdini et al., 2006), visitors' values (Walker and Moscardo, 2014) et al. The research tendency in the field of interpretation is that researchers gradually attach importance to affective outcomes of interpretation, especially the affective outcomes of interpretation at the setting of cultural heritage tourism. The study sites concerning interpretation are mainly national parks, recreation areas, nature-basted sites and wild animals' reserves et al. This present review finds that very few studies select cultural heritage sites as their study sites.

The limitations of the existing research are as follows: firstly, a majority of studies are based on simple research models, lacking scientific theoretical basis (Jensen et al., 2011); secondly, in studies of interpretive outcomes, it is generally assumed that interpretive services involved in the studies are of high quality, having appropriate contents and the information conveyed through interpretive programs are satisfying. Such an assumption might lead to the research findings lacking scientific evidence; thirdly, most of the studies conducted surveys among visitors about the outcomes of interpretation right after they experience interpretive services and very few studies conducted surveys a period of time after visitors experience interpretive services (Hughes, 2013). One of the other problems is that most of the studies depend too much on visitors self-report for collecting data and effectively designed experiments are seldom used for data collection.

In the future research of interpretation, scholars should value a combination of empirical study with relevant theory and attach more importance to visitors' affective change after they experience interpretive services. For studies concerning behavioral outcomes of interpretation, scholar should focus on the investigation of actual behaviors of visitors, employ more appropriate evaluation tool to assess cognitive, affective and behavioral outcomes of interpretation to make the research methods in this field more reasonable.

\section{REFERENCES}

[1] Knudson, D., Cable, T., \& Beck, L. (2003). Interpreting cultural and natural resources, Second Edition. Venture Publishing, Inc. State College, PA 16801

[2] Ham, S., Weiler, B..(2006). Development of Research-based Tool for Evaluating Interpretation. Sustainable Tourism. Pty Ltd. 1-53.

[3] Papathanassiou-Zuhrt, D., Sakellaridis,O. (2006). Transinterpret II Transnational Quality Management in Heritage Interpretation within the Framework of C.I. leader--the Case of Greece. 1-20.

[4] Tilden, F. (1977). Interpreting Our Heritage. The University of North Carolina Press. P33.

[5] Skibins, J., Powell, R.(2011). Exploring Empirical Support for Interpretation's Best Practices. Journal of Interpretation Research.17(1):25-44.

[6] Wei, D.Y. (2009). Building an Evaluation Framework of Environmental Interpretation for Chinese Geoparks - Case Stduy of Yuntaishan World Geopark. Dissertation.

[7] Moscardo, G. (2014) Interpretation and Tourism: Holy Grail or Emperor's Robes?. International Journal of Culture, Tourism and Hospitality Research, 8(4):462 - 476.

[8] Hughes, M. (2004). Influence of varying intensities of natural area on-site interpretation on attitudes and knowledge. $\mathrm{PhD}$ thesis, Murdoch University.

[9] Forist, B. E. (2003) .Visitor use and evaluation of interpretive media: A report on visitors to the National Park System, The National Park Service Visitor Services Project. National Park Service, U.S. Dept. of the Interior.

[10] Black, R., Davidson, P. (2013). Guided Cave Interpretation: Principles from Profession. Journal of Interpretation Research.8(2): 18-21.

[11] Io, M.U. (2013). Testing a Model of Effective Interpretation to Boost the Heritage Tourism Experience: a Case Study in Macao. Journal of Sustainable Tourism. 21(6): 900-914

[12] Stern, M., Powell, R. (2014). From The Difference Between Good Enough and Great: Bringing Interpretive Best Practices to Life. Journal of Interpretation Research, 18(2) :79-100.

[13] Ivey, J.R., Bixler, R.D. (2013). Preparing to Be an Interpretive Naturalist: Opinions from the Field. Journal of Interpretation Research, 18(1): 89-96.

[14] Ballantyne, R., Packer, J., Hughes, K.(2008). Environmental Awareness, Interests and Motives of Botanic Gardens Visitors: Implications for Interpretive Practice. Tourism Management, (29): 439-444.

[15] Yamada, N., Knapp, D.H. (2007). Adult Participants' Preferences for Interpretation at a Japanese Nature. Journal of Interpretation Research, 14(2): 59-63

[16] Poria,Y., Biran, A., Reichel, A. (2009). Visitors' Preferences for Interpretation at Heritage Sites. Journal of Travel Research, 48(1): 92-105.

[17] Goodrich, J.L., Bixler, R.D.(2010). Getting Campers to Interpretive Programs: Understanding Constraints to Participation. Journal of Interpretation Research, 17(1):50-70.

[18] Harrison ,M., Banks, S. (2009). An Evaluation of the Impact of River Guide Interpretation Training on the Client's Knowledge and Interest Regarding the Environment. Journal of Interpretation Research, 16(1): 39-43

[19] Morgan, M., Hwang, G.(2014). Perception of Thematic-Based Interpretation at the Jefferson National Expansion Memorial-A Study of Korean Visitors. Journal of Interpretation Research, 19(2): 25-37.

[20] Hill, J., Woodland,W., Gough, G.(2007). Can Visitor Satisfaction and Knowledge About Tropical Rainforests be Enhanced Through Biodiversity Interpretation, and Does this Promote a Positive Attitude Towards Ecosystem Conservation? Journal of Ecotourism.,6(1): 7585 .

[21] Zeppel, H., Muloin, S. (2008). Conservation Benefits of Interpretation on Marine Wildlife Tours. Human Dimensions of Wildlife: An International Journal, 13(4): 280-294. 
[22] Ham, S., Weiler, B.(2007). Isolating the Role of On-site Interpretation in a Satisfying Experience. Journal of Interpretation Research.12(12): 5-24.

[23] Powell, R., Stern, M.(2013). Speculating on the Role of Context in the Outcomes of Interpretive Programs. Journal of Interpretation Research, 18(1):61-78.

[24] Huang, S.S., Weiler, B., Assaker, G. (2015). Effects of Interpretive Guiding Outcomes on Tourist Satisfaction and Behavioral Intention. Journal of Travel Research, 54(3): 344-358.

[25] Powell, R., Stern, M. (2014). Is It the Program or the Interpreter? Modeling the Influence of Program Characteristics and Interpreter Attributes on Visitor Outcomes. Journal of Interpretation Research, 18(2): 45-60.

[26] Kim, A. K., Airey, D., Szivas, E. (2011). The Multiple Assessment of Interpretation Effectiveness: Promoting Visitors' Environmental Attitudes and Behavior. Journal of Travel Research,50(3): 321-334.

[27] Weiler, B., Smith, L.(2009). Does More Interpretation Lead to Greater Outcomes? An Assessment of the Impacts of Multiple Layers of Interpretation in a Zoo Context. Journal of Sustainable Tourism, 17(1): 91-105.

[28] Ham, S. (1983). Cognitive Psychology and Interpretation: Synthesis and Application. Journal of Interpretation, 8 (1):11-27.

[29] Kohl, J., Eubanks, T.( 2009). A Systems-Based Interpretive Planning Model that Links Culturally Constructed Place Meanings and Conservation. Journal of Interpretation Research, 13(2): 59-74.

[30] Ham, S. (2009). Interpretation to Protection: Is There a Theoretical Basis? Journal of Interpretation Research, 14(2): 49-57. 